\title{
EDUCATIONAL IMPLICATIONS OF TACTILITY IN ART
}

\section{Marilyn Wolf}

Tactility, the responsiveness to stimulation of the sense of touch, has been given minimum recognition as it relates to art and education. It is the visual sense that is more often given priority. In fact, we refer to painting and sculpture as the "visual arts".

My interest in the subject of tactility was probably first motivated by past difficulties in learning through the traditional classroom methods. This was particularly true at the middle and high school levels. I was able to grasp concepts best through the problem solving challenges presented to me in my art classes. It was this experience in the art class, my empathy for those who find learning difficult, and an unsolved dilemma that I have personaliy battled through the years over my natural urge to touch everything while trying to observe cultural taboos, that led me to this area of study.

Our western culture is visually oriented. Consequently, so is our education system. Visual exercises in reading and writing fill the majority of class time through the school years, forcing children to adapt as best they can to that single approach to learning. Not all students, however, are able to learn by using this sense alone. Viktor Lowenfeld wrote in his discussion of visual and haptic learning types that,

"Seeing may...become an inhibitory factor when forced upon an individual who does not use his visual experiences for creative work." (1957, p. 262)

Research shows that, given the opportunity to use and deverop other senses, students of all ages are able to learn more easily. (Baney 1980, Moholy Nagy 1947, Lowenfeld 1957). Why then, has so little recognition been given to the tactile sense as a means to greater learning and expression? It can be attributed to several things. Our cultural taboo toward touching is one. Churchill (1970) suggests that its psychological tie to eroticism is too strong for our culture to permit exploratory touch. A second reason is the adolescent reversal of the sequential development of the human senses. (Montague, 1978) The first sense to develop is the tactile sense, the second is auditory, and the third is the visual. But, states Ashley Montagu, the order of precedence reverses as the child approaches adolescence.

"It is much more important to experience tactile and auditory stimulations in the developing years than it is to experience visual ones. As soon, however, as one has developed through one's tactile and auditory senses, the know-how of being human, vision becomes by far the most important of the senses." (p. 249) 
Frances Herring's (1948-49) research into this problem offers three explanations for the lack of recognition given to the tactile sense. 1) Touch, like taste and smell is predominantly utilitarian in function, 2) there are no intrinsic principles of order in tactile sensations, and 3 ) touch, unlike sight and hearing is incapable of expressing the larger and deeper life experiences, of expressing values.

It is my belief, however, that the visual sense and the tactile sense cannot be separated. The two-dimensional sense of vision is given tridimensionality through touch. Sight gives information of distance, while touch gives information of proximity. Use of the familiar phrase, "Let me see it," actually means, let me touch it, let me validate its existence. Montague points out another aspect of the visual and tactile sensory modalities:

"The tactile quality of vision is apparent in the touching of another with the eyes. Hence one avoids looking or staring at strangers except in certain... acceptable situations." (p. 248)

The visual and tactile get bound up in one another. The mere visual appearance of an object is sufficient to stimulate clear images of temperature, texture, weight, and resistance. (Parkhurst, 1930) Berenson (1953) called this physical reaction to what is seen, "ideated sensations", something an artist seeks to elicit from the observer with his work.

Through art, an individual expresses what he or she sees and feels. In the act of creation, the artist uses both sight and touch. The observer is most often limited to using the visual sense in viewing the artist's work. But the artist who is successful, will stimulate tactile sensations in the observer, making the act of observation more complete.

I believe that a greater emphasis on tactile learning in conjunction with visual learning, through art education in the schools, would offer new approaches to teaching. This would be particularly beneficial to upper level elementary and middle school level children who lack tactile experiences in learning. Rudolph Arnheim explains:

"Our entire educational system continues to be based on the study of words and numbers. In kindergarten, to be sure, our youngsters learn by seeing and handling handsome shapes, and invent their own shapes on paper or in clay by thinking through perceiving. But with the first grade of elementary school the senses begin to lose educational status." (1969 p. 2).

Tactile approaches to learning would assist those who have difficulty acquiring knowledge visually as well as offering one more means to learning for those who are able to acquire knowledge successfully through visual means (Lowenfeld, 1957).

\section{Marilyn Wolf 81}


My research is presently in the beginning stages and is somewhat philosophical. As a preliminary step, I coordinated a fairly large tactile art exhibit in Athens, Georgia, and gathered data concerning observer reactions to having touched the sculpture on exhibit. I found that the pieces which had been touched were remembered more clearly than those which had not. Tactile observers took a greater interest in the art work, and generally took a longer time inspecting each piece of work touched, as compared to those pieces that were only observed visually. I now feel that my next step must be to develop an instrument that will measure tactile perception.

As a base from which to develop my work, I am using information gathered from recent studies such as that of Baney (1980) who attempted to show that the use of both the visual and tactile senses results in better replication of form, and Berieka, who examined the relationship of tactile perception ability to intelligence and reaching achievement in first and third grade children to predict later reading achievement.

Others have begun the task of demonstrating the value of recognizing the tactile sense in art activities and in general education. I hope my research will enable further recognition of the values of tactility in both.

\section{REFERENCES}

Arnheim, Rudolph. Visual thinking. Berkeley in Los Angeles: 1969. University of California Press.

Baney, Ralph $R$. The tactual perception of three dimensional form as a basis for drawing and modeling and for appreciation of three-dimensional art. Unpublished Doctoral Dissertation, University of MaryTand, CoTTege Park, 1980.

Berenson, Bernard. Aesthetics and history. New York: Pantheon Books, 1953.

Churchi11, Angiola. Art for adolescents. New York: McGraw Hill, 1970. Herring, Frances W. Touch - the neglected sense. Journal of Aesthetics and Art Criticism, 1948-49, 7, 199-215.

Lowenfeld, Viktor. Creative and mental growth. New York: Macmillan Company, 1957.

Moholy Nagy, Lazslo. Vision in motion. Chicago: Paul Theobald, 1947. Mantagu, Ashley. Touching. New York: Harper and Rowe, Publ ishers, 1978. Parkhurst, Helen Huss. Beauty: an interpretation of art and the imainative life. New York: Harcourt, Brace and Company, 1930. 